\title{
«LAS NEIREIDAS DEL NORTE»: PUERTOS E IDENTIDAD URBANA EN LA FACHADA CANTÁBRICA ENTRE LOS SIGLOS XII-XV
}

\author{
Jesús Ángel Solórzano Telechea ${ }^{1,2}$ \\ Universidad de Cantabria
}

\section{RESUMEN}

La identificación de los habitantes de los puertos del Norte de la Península en la Edad Media se asentó, en primer lugar, sobre la pertenencia a un espacio de la Corona privilegiado por los fueros y privilegios económicos dados por los reyes. En segundo lugar, sobre la red de relaciones personales e institucionales que fueron capaces de tejer sus habitantes gracias a las rutas marítimas y, por último, en una identidad política de los grupos sociales, asentada en valores contrapuestos, según se trate de la oligarquía o del Común, que les confería un determinado papel social.

Palabras clave: Identidad urbana, puertos, norte de la Península Ibérica, Edad Media.

\section{ABSTRACT}

The identity of the town-ports' inhabitants in Northern Iberian in the Middle Ages was based, first of all, on the belonging to the Crown's territory which was favoured by the territorial and economic privileges granted by the kings. Secondly, urban identity was based on the inhabitants' ability of developing personal and institutional links with other lands, towns and people, which was

1 Doctor en Historia. Profesor Titular. Departamento de Ciencias Históricas. Facultad de Filosofía y Letras. Universidad de Cantabria. 39005. Santader. C.e.: jesusangel.solorzano@unican.es.

2 Este trabajo se inscribe en el marco de las tareas del proyecto de investigación "Ciudades y villas portuarias en la articulación del litoral atlántico en la Edad Media», financiado por el Ministerio de Ciencia e Innovación, referencia HAR 2009-08474. 
given easier by the maritime routes and, finally, urban identity was based on the conflicting political identities of the social groups (oligarchy and Commons) that gave them a certain social role.

Keywords: Urban identity, tow-ports, northern Iberian, Middel Ages

A finales de la Edad Media, las diversas identidades urbanas estaban plenamente asentadas en la Corona de Castilla. Las ciudades y villas se hallaban integradas en una red jerárquica de centros urbanos, que iba desde las prósperas ciudades de Burgos y Sevilla, hasta las cerca de cincuenta villas de la fachada Cantábrica. Una de las cuestiones más interesantes de la identidad urbana en la Edad Media viene dada por la misma definición de la «identidad». Rogers Brubaker ha realizado recientemente una redefinición del concepto de «identidad» como categoría de análisis, que ha sustituido por el de «identificación» al objeto de centrar el problema no en los rasgos de caracterización, sino en las personas que realizan y participan de la identificación ${ }^{3}$. En todos los casos, nos encontramos con unas realidades urbanas que presentan ciertos rasgos comunes en lo político, lo económico y lo social, de los que participan, en mayor o menor medida, todos los habitantes ${ }^{4}$.

\section{LAS INMUNIDADES URBANAS: FUEROS Y PRIVILEGIOS}

La promoción urbana del norte peninsular comenzó en el siglo XII para responder a unos objetivos concretos: económicos, sociales, demográficos, políticos y estratégicos ${ }^{5}$. Desde mediados de esa centuria, los monarcas castellanos cada vez estuvieron más próximos al mar6. Se trata de un movimiento que responde a un proyecto específico de los reyes por crear un embrión de política marítima y se

3 BRUBAKER, R., Ethnicity Without Groups. Harvard University Press, Cambridge, 2004, p. 28-63. GOLDBERG, P. J. P., «Urban Identity and the Poll Taxes of 1377, 1379, and 1381», en The Economic History Review, New Series, Vol. 43, n. 2, 1990, pp. 194-216. HUDDY, L., «From Social to Political Identity: A Critical Examination of Social Identity Theory», en Political Psychology, Vol. 22, N. 1, 2001, p. 127-156.

4 VAL VALDIVIESO, M.I., «La identidad urbana al final de la Edad Media», en Anales de Historia Medieval de la Europa Atlántica, 1, 2006, pp. 5-28.

5 ARÍZAGA BOLUMBURU, B.; BOCHACA, M.: «Caracteres généreaux des villes portuaires du nord de la Péninsule Ibérique», Ports Maritimes et ports fluviaux au Moyen Age. París, 2005, pp. 63-78.

6 SOLÓRZANO TELECHEA, J.A, «Medieval Seaports of the Atlantic Coast of Spain», en International Journal of Maritime History, XXI, 2009, pp. 81-100. SOLÓRZANO TELECHEA, J.A., »La fundación y promoción de las 'villas nuevas' en el litoral Atlántico del Norte peninsular durante el reinado de Alfonso X», en El mundo urbano en la Castilla del siglo XIII, vol. II, Sevilla, 2006, p. 315-328. SOLÓRZANO TELECHEA, J.A, «Los puertos del Rey: síntesis interpretativa del fenómeno urbano en el Norte de España durante los siglos XII y XIII», en Temas Medievales, 17, 2009, pp. 207-228. 
inscribe en el proceso de afirmación y expansión de la monarquía frente a los poderes feudales en la frontera marítima del reino ${ }^{7}$.

La emergencia de los núcleos urbanos portuarios en esta dilatada costa fue un fenómeno tardío, que no comenzó a manifestarse de forma sostenida e intensa hasta la segunda mitad del siglo XII, tras la muerte del monarca Alfonso VII en 1157 y la consiguiente separación de los reinos de León y Castilla. Si bien este rey realizó algunas repoblaciones aisladas en el frente marítimo astur-galaico concediendo fueros en fecha imprecisa a Ferrol y, en 1155, a la villa asturiana de Avilés, habrá que esperar al reinado de sus suscesores al frente de estos reinos, ya separados, de León y Castilla -Fernando II y Alfonso IX en la orla costera de León y Alfonso VIII en la de Castilla- para asistir a la promoción intensa de fundaciones urbanas en la costa. Esta actividad fundacional, que continuará a lo largo de los dos siglos siguientes, dio origen a la formación y consolidación de una densa red de centros urbanos costeros llamados a desempeñar un activo protagonismo.

En la costa de Galicia, los monarcas Fernando II (1157-1188) y Alfonso IX (1188-1230) centraron sus esfuerzos urbanizadores en la constitución de centros portuarios realengos, capaces de neutralizar la actividad económica del señorío eclesiástico de la mitra compostelana y su puerto de Padrón ${ }^{8}$. De esta manera, surgieron centros urbanos como Noya (1168) y Pontevedra (1169), si bien pronto caerían en manos de la sede compostela. Alfonso IX continuó la obra de sus antecesores con la creación de Ribadeo en 1182, a la que seguirían otras como Vivero (1190?), Laguardia (ca. 1200), Bayona (1201), Betanzos (1219), y, sobre todo, La Coruña (1208), el más importante puerto de realengo de Galicia, gracias a su dinamismo mercantil $1^{\circ}$. Aún en la segunda mitad del siglo XIII, Alfonso X dio un gran impulso a la creación de puertos en Galicia. La primera villa fundada por Alfonso X fue Ortigueira en 1255, a la cual el monarca le concedió un privilegio fundacional ambicioso, ya que de una parte les otorgaba la creación de una feria anual y, de otra, eximía del pago del portazgo a los mercaderes que arribasen con sus mercancías (vinos, paños, sal), excepto del que debían pagar al rey, en las mismas condiciones que los navíos que llegaban a La Coruña. Por estas fechas, también surgió el puerto de Cedeira, con lo que el monarca se asentaba fuertemente en la zona de Cabo Ortegal. Algunos años después, en 1270, Alfonso X fundó la villa de Puentedeume, si bien en este caso el objetivo no fue mercantil -hubiera sido un vano intento, debido a la presencia cercana de los

\footnotetext{
7 AGUIAR ANDRADE, A., «A estratégia régia em relação aos portos marítimos no portugal medieval: o caso da fachada atlântica», en Ciudades y villas portuarias del Atlántico en la Edad Media. I Encuentros Internacionales del Medievo-Nájera, Logroño, 2005, pp. 57-90.

8 FERREIRA PRIEGUE, E., Galicia en el comercio marítimo medieval. La Coruña, 1988, pp. 81-82.

9 BARRAL RIVADUlLA, D., La Coruña en los siglos XIII al XV. La Coruña, 1997.
} 
potentes puertos de Ferrol, Neda y Betanzos-, sino que se basó en fortalecer la autoridad regia y controlar una zona con fuerte presencia de la pequeña nobleza local, precisamente en una área estratégica como era el puente sobre el río Eume. Asimismo, en las proximidades de La Coruña, surgió Ferrol, que fue mencionado como puerto con aduana en el Ordenamiento de 1268 y comenzaba a poblarse la Puebla de Muros, en la ría de Noya, aunque no recibiría su fuero hasta 1286, ya en el reinado de Sancho IV ${ }^{10}$.

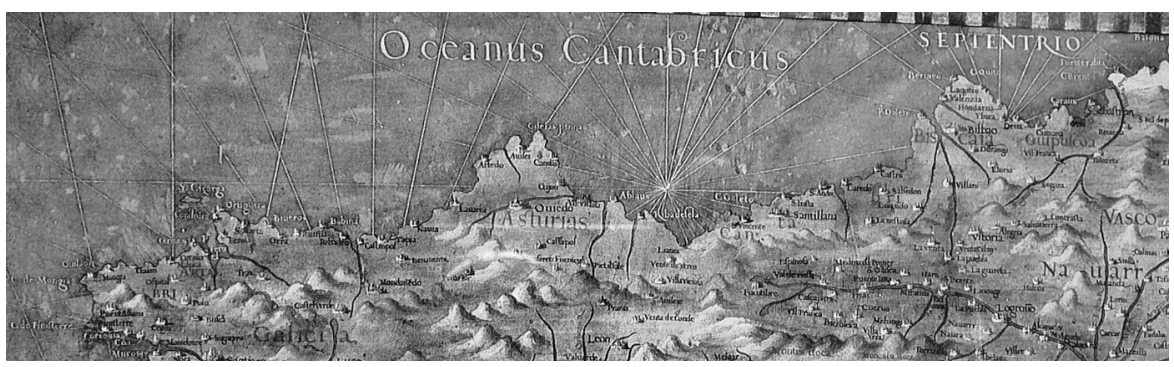

Figura 1. Costa Cantábrica (ca. 1565). Sala Delle Carte Geografiche. Palazzio Vecchio de Florencia

En la costa de Asturias, el proceso generador de las villas o pueblas nuevas se inició con Avilés a principios del siglo XII, aunque la copia más antigua de su fuero está fechada en torno a 1155. Es posible que fuera Alfonso VI quien otorgó carta de población a esta villa, según se constata por la datación radiocarbónica de la muralla ${ }^{11}$. Tras lo cual se fundaron Llanes (hacia 1225) y Pravia (hacia 1230). Pero fue en la segunda mitad del siglo XIII cuando la repoblación urbana recibió en Asturias un impulso decisivo por obra de Alfonso X, quien reforzó el territorio de realengo a partir de 1268. Ese año, el monarca procedía a «refundar» Llanes, que ya contaba con una carta puebla concedida por alfonso IX (1225); dos años después, en 1270, otorgó fuero a Gijón, y por estos años hacía lo mismo con Valdés (Luarca), Roboredo y Maliayo (Villaviciosa) ${ }^{12}$. Igualmente, a Alfonso X se le atribuye la fundación de Ribadesella, Candás y Luanco. En Asturias, la política regia de repoblación urbana tropezó con las interferencias de

${ }^{10}$ FERREIRA PRIEGUE, E., «El fenómeno urbano medieval en Galicia», J.A. SOLÓRZANO TELECHEA B. ARÍZAGA BOLUMBURU (Eds.). El fenómeno urbano medieval entre el Cantábrico y el Duero. Santander, 2002, 367-420.

${ }^{11}$ FERNÁNDEZ PÉREZ, A.; FRIERA SUÁREZ, F. (Coords.), Historia de Asturias. Oviedo, 2005, p. 235.

12 RUIZ DE LA PEÑA, J.I., Las «polas» asturianas en la Edad Media. Estudio y Diplomatario. Oviedo, 1981. 
los señoríos eclesiásticos. Un ejemplo paradigmático de los conflictos entre los distintos espacios jurisdiccionales se produjo en la Ría de Ribadeo, límite natural entre las sedes episcopales de Oviedo y Mondoñedo. De una parte, próxima a la desembocadura de la ría, donde se encontraba la villa de Ribadeo (1182), Alfonso X creó la puebla de Roboredo en 1282, justo en la orilla opuesta, lo que generó una rivalidad entre ambos puertos, a la que se quiso poner término con la firma de un acuerdo para el uso de la ría, pero tras ello el obispo de Oviedo complicó el statu quo de la zona al crear la villa de Castropol en 1298, con lo que entraban en conflicto tres ámbitos jurisdiccionales: la villa de Ribadeo (Obispado de Mondoñedo), la villa de Castropol (Obispado de Oviedo) y Roboredo (Realengo). Finalmente, Castropol acabaría eclipsando a Roboredo ${ }^{13}$. Entre el último tercio del siglo XIII y principios del XIV, surgieron otras dos villas portuarias en Asturias: Navia y Ribadesella.

En el sector central y oriental del Cantábrico, el rey Alfonso VIII desplegó un ambicioso programa de creación de villas, llamadas a desempeñar un destacado papel en la historia comercial y pesquera del reino de Castilla. Inicialmente, la atención de este monarca se centró en el reducido frente litoral sometido a su autoridad hasta 1200, otorgando cartas forales a Castro Urdiales (1163), Santander (1187), Laredo (1200) y San Vicente de la Barquera (1210) ${ }^{14}$. Desde la separación de los reinos de Castilla y de León en 1157, tras la muerte de Alfonso VII, hasta la incorporación a Castilla de Guipúzcoa y el Duranguesado hacia el año 1200, el litoral cántabro fue la única salida al mar del reino de Castilla, lo que hacía de estas tierras norteñas un objetivo económico y político de suma importancia estratégica para la monarquía. El matrimonio de Alfonso VIII con Leonor Plantagenet en 1170, hija de Enrique II y Leonor de Aquitania, que incluía La Gascuña como dote y el puerto de Santander como arras, abría nuevas perspectivas internacionales para la monarquía y el reino de Castilla. Tras la recuperación de la costa vasca en 1200, donde el monarca navarro, Sancho el Sabio, había otorgado carta foral a San Sebastián en 1180, la reducida costa guipuzcoana se esmaltó de nuevas e importantes fundaciones portuarias: Fuenterrabía (1203), Guetaria (1209) y Motrico (1209), a las que se sumó, años después y por decisión de Fernando III, la de Zarauz (1237). La costa guipuzcoana se completaría en el siglo XIV con otras cuatro villas: Rentería (1320), Deva (1343), Zumaya (1347) y Orio (1379). Hay que señalar la tardía incorporación de la costa vizcaí-

${ }^{13}$ ARÍZAGA BOLUMBURU, B., «Conflictividad por la jurisdicción marítima y fluvial en el Cantábrico en la Edad Media», Ciudades y villas portuarias del Atlántico en la Edad Media. Nájera-Encuentros Internacional del Medievo (2004). Logroño, 2005, P. 17-56.

${ }^{14}$ SOLÓRZANO TELECHEA, J.A.: «El fenómeno urbano medieval en Cantabria», El fenómeno urbano..., 
na a la vida urbana en el litoral cántabro-atlántico, ya que la primera de sus villas portuarias, Bermeo, no se fundó hasta 1236, por iniciativa del señor Lope Díaz de Haro. A esta villa, se incorporaron Plencia (1299), Bilbao (1300), Portugalete (1322), Lequeitio (1325) y Ondárroa $(1327)^{15}$.

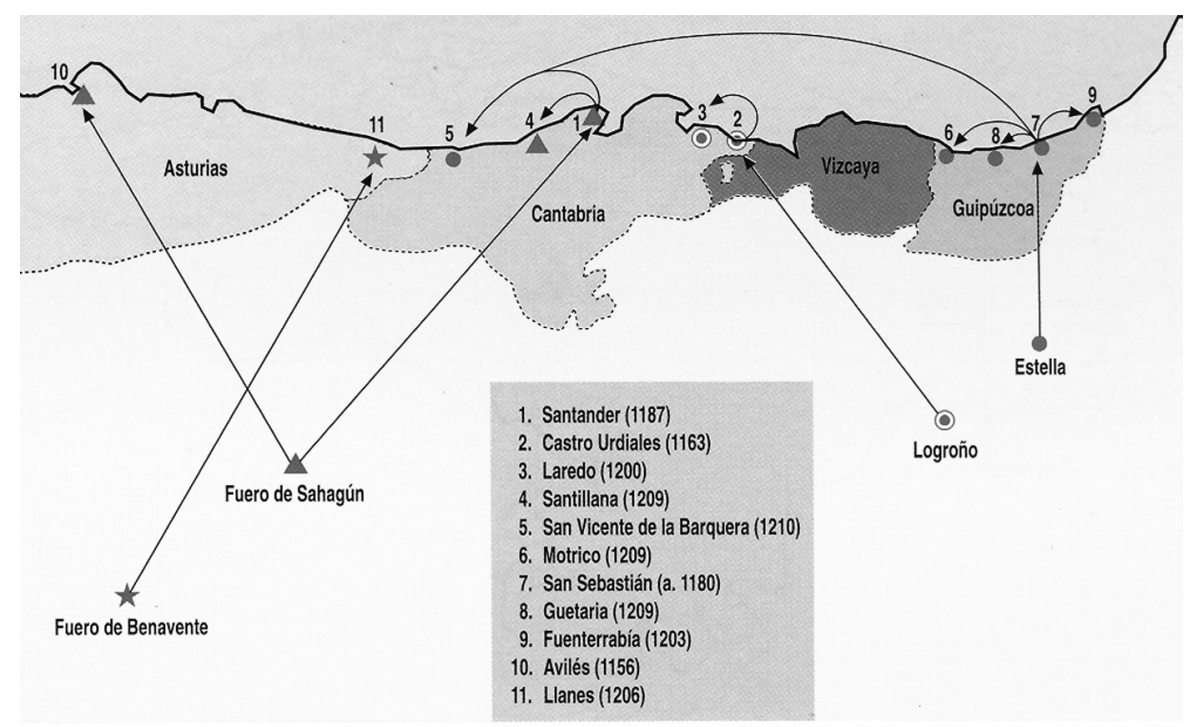

Figura 2. Filiación de los fueros de las villas de la Costa Cantábrica

Una vez fundadas las villas portuarias, la política regia, en una segunda fase, se dirigió a situarlas en un plano ventajoso respecto a los señoríos eclesiásticos que las circundaban ${ }^{16}$. Así, la política real de fundación de nueva villas portuarias fue acompañada de la concesión de exenciones generosas de impuestos sobre la explotación y comercialización de las mercancías, así como de medidas proteccionistas, que en su mayor parte fueron otorgadas por el rey con anterioridad a la crisis de 1272, año de la revuelta de un importante sector de la nobleza contra el monarca ${ }^{17}$.

${ }^{15}$ ARÍZAGA BOLUMBURU, B., «El litoral vasco peninsular en la época pre-urbana y el nacimiento de San Sebastián», en Lurralde, 13, 1990. B. ARÍZAGA BOLUMBURU. Urbanística medieval (Guipúzcoa). San Sebastián, 1990.

${ }^{16}$ SOLÓRZANO TELECHEA, J.A., «La fundación y promoción de las 'villas nuevas' en litoral Atlántico del Norte peninsular durante el reinado de Alfonso X», en El mundo urbano en la Castilla del siglo XIII. 750 Aniversario de la Fundación de Ciudad Real. Actas del Congreso. Ciudad Real, 2006, p. 315-328.

${ }^{17}$ LADERO QUESADA, M.A., «Las reformas fiscales y monetarias de Alfonso X como base del 'Estado Moderno'», en M. RODRÍGUEZ LLOPIS, Coord. Alfonso X. Aportaciones de un rey castellano a la construcción de Europa. Murcia, 1997, p. 37-42. 
Alfonso X reforzó la autoridad regia en la frontera marítima del reino por medio de la concesión de privilegios a las poblaciones, cuya finalidad era «acreçerlos en sus bienes e leuarlos al adelante, e que sean más ricos e valan más», con lo que se atrajo el apoyo de las elites urbanas de aquellas villas ${ }^{18}$. La prioridad más acuciante de aquellos puertos era asegurarse el abastecimiento de la población, así como la propia vitalidad económica, que giraba en torno a la actividad comercial. Para ello, las villas necesitaban una balanza comercial equilibrada y la protección de los productos de la tierra, que en las Cuatro Villas de la Costa eran el vino, la sal y el hierro.

Los puertos cantábricos que más exenciones recibieron durante el reinado de Alfonso X fueron los de las Cuatro Villas de la Costa de la Mar. La primera villa privilegiada fue Santander ${ }^{19}$. En 1253, el monarca le confirmaba su exención de pagar portazgo en Población, lugar situado en el Camino de Santiago, entre Frómista y Revenga. Dos años después, en 1255, el rey eximía de pagar portazgo a los vecinos de Santander en todo el reino, salvo en Sevilla y Murcia. Junto con Santander, ese mismo año, fueron favorecidos por Alfonso X, los puertos de Castro Urdiales y Laredo con un privilegio de franquicia de portazgo en Medina de Pomar, paso obligado de las mercancías en su camino hacia la costa y viceversa. En el caso de Laredo, se sumó ese año la concesión de un privilegio por el que se extendía la exención de portazgo a todo el reino, salvo Murcia y Sevilla, así como la facultad de pescar y salgar en todos los puertos de Castilla, León y Galicia, con la única condición de que comprasen la sal en los alfolíes reales y pagasen el diezmo de los pescados al rey. Tanto en el caso de Santander, como en el de Laredo, Alfonso $\mathrm{X}$ reconoce el apoyo militar prestado por estas villas en la conquista de Sevilla de 1248 , junto con el deseo de que las poblaciones prosperen con esas concesiones fiscales ${ }^{20}$. No obstante, la villa de Santander aun recibió más mercedes, pues en 1263 le exoneraba del portazgo en las dos ferias anuales de Valladolid. El deseo del monarca consistía en establecer una vía directa de tránsito de mercancías entre Santander y Valladolid, para lo cual dispensó de pagar portazgo en esa villa a los mercaderes de la costa Cantábrica (Ultra Pas), procedentes de Santander, y desvió el lugar donde se debía entregar el portazgo, desde Carrión a Monzón ${ }^{21}$.

\footnotetext{
18 SOLORZANO TELECHEA, J.A., Patrimonio documental de Santander en los archivos de Cantabria. Documentación medieval, Santander, 1998, doc. 2.

${ }^{19}$ SOLÓRZANO TELECHEA, J.A., Santander en la Edad Media: patrimonio, parentesco y poder. Santander, 2002.

${ }^{20}$ CUÑAT CISCAR, V., Documentación medieval de la villa de Laredo. 1200-1500, Santander, 1998 , docs. 6,7 y 8.

${ }^{21}$ SOLORZANO TELECHEA, J.A:, Patrimonio documental de Santander en los archivos de Cantabria, Santander, 1998, doc. 5.
} 
Otra de las medidas alfonsinas con relación a los puertos consistió en la protección de las mercancías que servían como moneda de canje en las transacciones comerciales, en especial, la sal y el vino. Las villas cántabras eran lugares de acarreo, deficitarios de cereales panificables, y con el libre intercambio de mercancías conseguían estar abastecidas de este producto de primera necesidad. En 1276, el concejo de Santander se quejaba de que cuando faltaba sal en el alfolí de la villa, los mercaderes se veían obligados a importarla de otras partes, pero los arrendadores del alfolí de la sal les pedían la cuarta parte de su valor, lo que perjudicaba a los mercaderes, que se negaban a acudir a Santander y ello conllevaba que la villa tampoco fuera proveída de pan. De igual manera, en 1281, el concejo de Santander dirigió al rey una carta por la que solicitaba la exención del diezmo del vino de su cosecha, que exportaban al extranjero ${ }^{22}$. Alfonso $\mathrm{X}$ accedió a ambas peticiones, pues entendía que se trataba de unas mercancías vitales para los intercambios de la villa con el exterior ${ }^{23}$. Por su parte, San Vicente de la Barquera fue el puerto que menos franquicias recibió de entre las Cuatro Villas de la Costa. Sólo nos constan las confirmaciones del fuero de la villa (1210) y la del privilegio de exención de portazgo en todo el reino, que le había otorgado Fernando III en 1241, que excluía las ciudades de Toledo, Murcia y Sevilla ${ }^{24}$.

Todas estas liberalidades regias vinieron a actualizar la presencia regia en el litoral atlántico y a situar las villas reales de la orla costera en una posición ventajosa respecto a los que no tenían esa condición, lo que además servía para renovar la relación contractual entre el rey y los mercaderes de esas villas. Tras el proceso fundacional y de protección de las villas portuarias, se produjo una nueva jerarquización del territorio del litoral cantábrico en función de su condición de centros canalizadores del tráfico mercantil. Según el ordenamiento de las Cortes de Jerez de 1268, en el que aparecen los puertos autorizados para el tráfico de mercancías, se cita como puertos más importantes a San Sebastián y Fuenterrabia en Guipúzcoa; a Santander, Laredo y Castro Urdiales en Cantabria; a Avilés en Asturias, y, en Galicia, a La Coruña, Ribadeo, Vivero, Betanzos, Ortigueira, Cederia, Ferrol, Bayona, La Guardia, Pontevedra, Padrón y Noya. Sin duda, este documento aduanero es un indicador del nivel de desarrollo alcanzado por estos centros urbanos del litoral norteño.

${ }^{22}$ MARTíNEZ DíEZ, G., Alfonso X y su proyección en Cantabria, Santander, 1987, p. 28-29.

${ }^{23}$ SOLORZANO TELECHEA, Patrimonio..., op. Cit., docs. 6 y 7.

${ }^{24}$ SOLÓRZANO TELECHEA, J.A.,; VÁZQUEZ ALVAREZ, R.; ARÍZAGA BOLUMBURU, B., San Vicente de la Barquera en la Edad Media: una villa en conflicto, Santander, 2004, doc. 2. 


\section{LA IDENTIDAD MARÍTIMA: MERCADERES, INSTITUCIONES Y CULTURA ATLÁNTICA}

La fundación de centros portuarios estableció las bases materiales y logísticas que permitieron el mantenimiento de las relaciones comerciales de Castilla con el exterior y reforzó la cohesión interna del reino por su parte Norte. Estas villas portuarias fueron una pieza fundamental de la economía de la Corona de Castilla. Lentamente en sus inicios a finales del siglo XII y a mayor velocidad desde finales del siglo XIV, se creó con mucho esfuerzo una ruta de comercio que en sentido transversal unía los puertos cantábricos con los del Mar del Norte. Uno de los grandes centros urbanos de aquella ruta comercial era Burgos y sus antepuertos norteños, en especial Bilbao y Santander ${ }^{25}$.

Desde principios del siglo XIII, los mercaderes comenzaron a tejer vínculos comerciales y pesqueros con los principales puertos de la fachada atlántica europea, entre los que pronto se detecta el de La Rochelle, el principal puerto francés en el Golfo de Vizcaya, frecuentado por las naves que hacían la ruta atlántica hasta Inglaterra y Flandes ${ }^{26}$. Así, en 1237, mercaderes de San Sebastián recibieron un salvoconducto que les permitía comerciar con los Cinco Puertos del sur de Inglaterra ${ }^{27}$. Estas conexiones comerciales comienzan a evidenciarse mejor a partir del matrimonio de Leonor de Castilla con Eduardo I y el tratado anglo-castellano de 1254. En 1260, diversos mercaderes aparecen alquilando casas en Southampton y de los 102 Registros de Deudas del puerto de Londres del año 1285, cuarenta y dos corresponden a mercaderes.

Con la finalidad de hacer progresar este comercio, en 1296, se creó una institución supralocal para la acción conjunta de las villas de la Hermandad de la Marina de Castilla, que agrupaba siete puertos del Cantábrico (San-

\footnotetext{
25 SUÁREZ FERNÁNDEZ, L., «Proyección atlántica castellana en el siglo XV : el mar y la tierra», en Actas del V centenario del Consulado de Burgos. Burgos, 1995, p. 25-30.

${ }^{26}$ FAVREAU, R., «La Rochelle, port français sur l'Atlantique au XIIIe siècle», en L'Europe et l'Océan au Moyen Age, París, 1988, pp. 62-63. RUIZ DE LA PEÑA, J.I., «El nacimiento de las villas costeras cántabro-atlánticas y su instrumentación jurídica (siglos XII-XIII)», en El Fuero de Laredo en el VIII centenario de su concesión. Santander, 2001, p. 156. RUIZ DE LA PEÑA, J.I., "Comercio a escala interregional e internacional: el espacio comercial astur-leonés y su proyección atlántica», en El comercio en la Edad Media, Logroño, 2006, pp. 39-91. FERREIRA PRIEGUE, E., «Las rutas marítimas y comerciales del flanco ibérico, desde Galicia hasta Flandes», en El fuero de San Sebastián y su época, San Sebastián, 1981, pp. 217-234.

${ }^{27}$ CHILDS, W.R., «Commercial relations between the Basque provinces and England in the Latter Middles Ages. Ca. 1200-ca. 1500», en Itsas, Memoria. Revista de Estudios marítimos del País Vasco, no 4, 2003, p. 55-64.
} 
tander, Laredo, Castro Urdiales, Vitoria, Bermeo, Guetaria, San Sebastián y Fuenterrabía) en respuesta al enfrentamiento con las villas gasconas, en especial, con Bayona, motivo por el cual se vetaron las relaciones comerciales con Inglaterra, Flandes y esta ciudad hasta que finalizara la contienda ${ }^{28}$. A pesar de ello, los villas del Cantábrico oriental no podían obviar las conexiones que mantenían con los vecinos puertos bajo autoridad inglesa, como Bayona y Burdeos, razón por la cual las villas de Castro Urdiales, Laredo y Santander firmaron en 1306 y 1309 sendos acuerdos con la ciudad Bayona con el beneplácito del monarca inglés Eduardo I, al igual que hicieron las guipuzcoanas en 1309,1311 y $1328^{29}$. De todo ello, podemos deducir que las villas marineras del Cantábrico oriental desarrollaron su propio juego, buscando desplegar su influencia militar o comercial en los puertos ingleses y franceses más pujantes, eliminando la concurrencia de otros países, que podrían haberse aprovechado del contexto político del momento para introducirse en esos mercados.

La institución de la Hermandad de la Marina de Castilla tuvo una breve existencia, pues a partir de mediados del siglo XIV, la unidad de acción de las villas portuarias frente al exterior la ejercieron los representantes de cada una de las marismas o provinçias marítimas, cuya fortuna vino marcada por la Guerra de los Cien Años y la neutralidad castellana hasta la Batalla naval de Winchelsea de 1350, que permitió hacer buenos negocios y aumentar la presencia de marineros y mercaderes en Flandes, Inglaterra y la costa occidental de Francia. Sin embargo, la segunda mitad del siglo XIV se caracterizó por los conflictos con los ingleses. Con la finalidad de apaciguar los enfrentamientos, que claramente perjudicaban el comercio, se establecieron varias concordias. En 1351 y 1353, se acordaron dos treguas entre el reino de Inglaterra y «Toutes Marismes $\&$ Costeres de Meer, Portz, Citees \& Villes de la Seignure le Rois de Castelle $E$ du Counte de Viscaye $\gg^{30}$, ampliadas en 1357, con el fin de hacer prosperar el comercio y, en 1404 y 1407, esta vez todos los puertos de la «Marisma de España» refrendaron sendas concordias con los puertos ingleses de La Gascuña para agilizar las relaciones mercantiles.

Precisamente, estos dos últimos acuerdos evidencian el grado de desarrollo de las redes urbanas portuarias existentes en el litoral atlántico pe-

\footnotetext{
${ }^{28}$ MORALES BELDA, F, La Hermandad de las Marismas. Barcelona: Ariel, 1974, p. 292.

29 SOLÓRZANO TELECHEA, J.A., Patrimonio documental de Santander en los archivos de Cantabria. Documentación medieval, Santander, 1998, docs. 18-22.

${ }^{30}$ RYMER, T., Foedera, convenciones, literae et cuiuscunque generis acta publica inter reges Angliae et alios quosvis imperatores, reges, pontifices, principes vel communitates, Vol. VI, Londres, 1727 , p. 29.
} 
ninsular. La Marisma de España comprende «çinco provinçias o marismas»: Guipúzcoa, Vizcaya, Castilla La Vieja, Asturias y Galicia, representadas por los concejos portuarios para avenirse a los acuerdos. La red de puertos más consolidada estaba integrada por las tres primeras provinçias («las marismas de Castilla, Vizcaya y Guipúzcoa»), mientras que las marismas de Asturias y Galiçia eran más débiles. Así se aprecia en la concordia de 1404 antes referida, en la que aparecen los procuradores de San Vicente de la Barquera, Santander, Laredo, Castro Urdiales, Bermeo, Bilbao, Lequeitio, Ondárroa, Motrico, Deva, Zumaya, Guetaria y San Sebastián, que representan a los puertos de las provincias de Guipúzcoa, Vizcaya y Castilla Vieja, pero están ausentes los de los puertos de Asturias y Galicia, a pesar de ser incluidos en el acuerdo. Por su parte, en la concordia de 1407, las villas marineras de Galicia y Asturias están presentes, aunque comparten tres procuradores. Esta debilidad en la acción denota la fragilidad de la red urbana portuaria gallega $^{31}$. Elisa Ferreira Priegue, recientemente, exponía que no es posible hablar en Galicia de un sistema portuario ni urbano. En primer lugar, debido a la existencia de la dicotomía entre puertos de realengo y de señorío. Desde la segunda mitad del siglo XII, las principales villas costeras, como Padrón, Burgo de Faro, Noya y Pontevedra, estaban en manos del arzobispo de Santiago. Sólo a principios del siglo XIII fructificaron Bayona do Miño (1201) y La Coruña (1208) como puertos de realengo. En segundo lugar, cada villa portuaria es un mundo propio, no hay intercambios ni mercados complementarios entre los puertos gallegos y nunca se constituyó una hermandad similar a la de Hermandad de la Marisma, aunque hubo algunos intentos ${ }^{32}$. He aquí la gran diferencia entre la red urbana portuaria del sector central y oriental del Cantábrico, donde el poder monárquico había logrado imponerse a los sistemas autónomos y dar unidad al litoral, y el sector asturgalaico, especialmente el gallego, donde los puertos monárquicos hubieron de competir con los señoriales.

\footnotetext{
${ }^{31}$ FERREIRA PRIEGUE, E., «Galicia en la Marisma de Castilla. La dinámica de los intercambios mercantiles», en ARÍZAGA BOLUMBURU, B.; SOLÓRZANO TELECHEA, J.A. (Eds.), Ciudades y villas portuarias del Atlántico en la Edad Media. Nájera. Encuentros Internacionales del Medievo 2004, Logroño, 2005, p. 173.

32 FERREIRA PRIEGUE, Galicia en el comercio..., op. cit., p. 505
} 


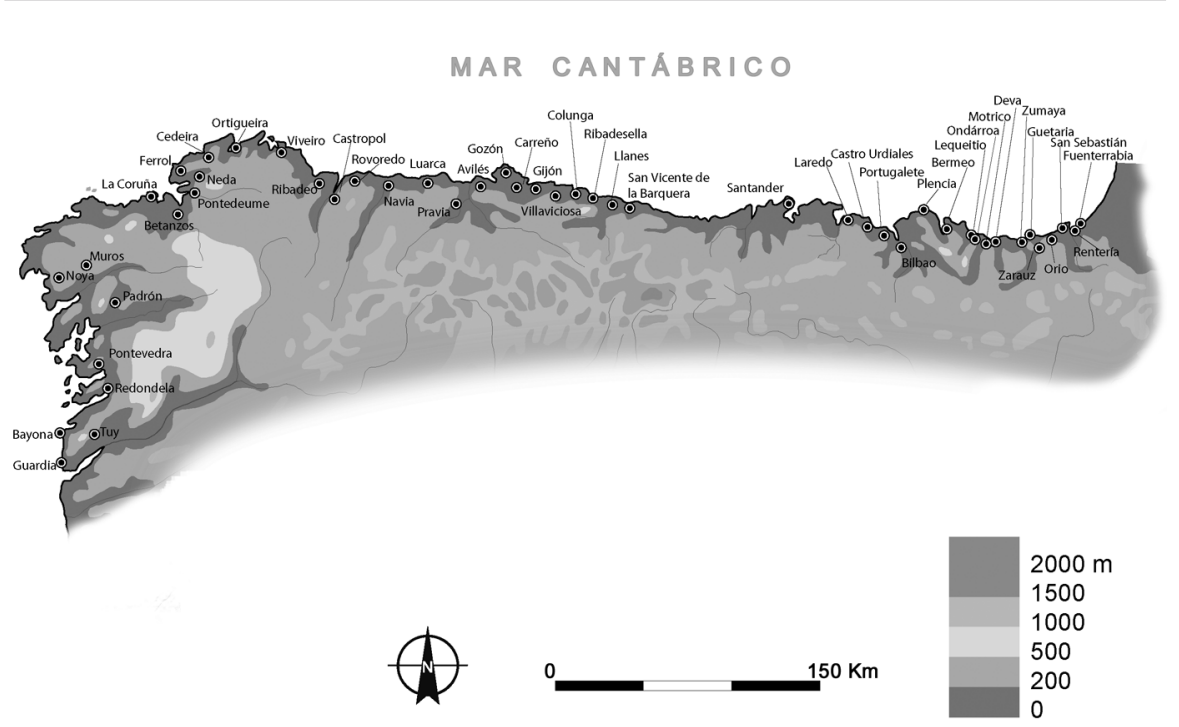

Figura 3. Villas portuarias del Norte Peninsular en la Edad Media

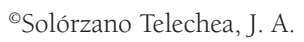

Al ocupar una posición central en las rutas marítimas entre el Mediterráneo y el Mar del Norte, las villas portuarias recibieron la influencia de los modelos y las modas culturales de ambos mares, en especial del Norte de Europa. Ni los enfrentamientos bélicos ni las Pestes lograron parar la construcción de redes de intercambio entre las orillas atlánticas. Los fenómenos culturales que se dieron fueron múltiples y no siempre limitados a una cultura de las élites.

En primer lugar, los hombres de la mar compartieron una cultura técnica, jurídica y lingüística con el resto de puertos atlánticos, derivada de experiencias comunes, que se concretó en un marco jurídico propio basado en la Leyes de Layrón o Roles de Olerón, el antiguo derecho propio de las sociedades marítimas y las cofradías de pescadores; en el uso de prácticas e instrumentos legales, como las cartas de fletamento y los préstamos a riesgo; en el tipo de barcos de origen gascón y anglo-bretón como la nao, la coca, el ballener y la barca; en las unidades de medida y embalaje, tales como el tonel de 900 litros, ... etc. Igualmente, hubo ciertas conexiones lingüísticas, ya que los navegantes emplearon una lengua franca, en la que todos se entendían, que aparece tanto en la documentación de los mercaderes, como en la referida al equipamiento de las embarcaciones y el lenguaje técnico de la navegación. También aparecen vocablos marineros tomados, por ejemplo, del neerlandés, como «arrumar», que significa colocar la carga de un buque y procede de la voz «ruim»; «cai», la misma palabra de origen 
gascón, que comparten los puertos de la fachada atlántica francesa y española para designar las construcciones portuarias; calfatage en francés y calafateado en castellano, que designa la acción de introducir entre dos tablas del casco de madera de un barco una mezcla de cáñamo con brea para evitar la entregada de agua; o el mismo tipo de embarcación llamado en castellano «pinaça», en francés «pinasse» $\mathrm{y}$ «pinnace» en inglés.

Una cuestión importante sobre el modelo cultural compartido por los puertos atlánticos es la relativa a la identidad marítima a través de la imagen de los sellos. Desde mediados del siglo XIII, los atributos iconográficos que representaban barcos o peces fueron asumidos comúnmente por las villas portuarias a lo largo del Atlántico, cuyo objetivo era indicar su identidad. Los puertos comparten la imagen de su sello, un navío sobre ondas en la mar, con un buen número de puertos atlánticos, tales como Fuenterrabía, Orio, San Sebastián, Zumaya, Lekeitio, Bermeo, Castro Urdiales, San Vicente de la Barquera, La Rochelle, Calais, Faversham, Dunwich, Hasting, Winchelsea, Southampton y Portsmouth, Dublín, Ámsterdam y Damne, o Gdansk, Wismar, Elbing y Dantzig. Una homogeneidad en la identidad marítima que muestra los fuertes intercambios mercantiles mantenidos a lo largo del litoral atlántico ${ }^{33}$.

\section{LAS IDENTIDADES SOCIOPOLÍTICAS: DE LAS «VOCES» AL SISTEMA INSACULATORIO.}

El tercer elemento sobre el que pivotó la identidad de los habitantes de las villas portuarias fue la conciencia «política» de los grupos sociales. En las villas del Norte peninsular, el sistema regimental se introdujo entre finales del siglo XIV y principios del $\mathrm{XV}^{34}$. La inestabilidad política de la segunda mitad del siglo XIV benefició a las elites urbanas. Los reyes de la dinastía Trastámara, desde Enrique II a Juan II, ofrecieron la ocasión de mejorar su posición dominante dentro de las villas a unas pocas familias, que formaban parte del bloque social rector (omes buenos, pecheros quantiados), algunos de cuyos integrantes se vieron rápidamente ennoblecidos a partir de entonces. El ennoblecimiento fue la recompensa que algunos miembros de la elite de poder urbana recibieron por su alianza con la

\footnotetext{
33 SOLORZANO TELECHEA, J.A., «Villas y redes portuarias en la fachada atlántica del norte peninsular en la Edad Media», en Val Valdivieso, Mª I.; Martínez, P. (Dirs.), Castilla y el mundo feudal. Homenaje a Julio Valdeón Baruque. Vol. I. Valladolid, 2009, p. 485-502.

${ }^{34}$ SOLÓRZANO TELECHEA, J.A., «Elites urbanas y construcción el poder concejil en las Cuatro Villas de la Costa de la Mar (siglos XIII-XV)», en Ciudades y villas portuarias del Atlántico en la Edad Media. Najera-Encuentros Internacionales del Medievo (2004). Logroño, 2005, pp. 187-230.
} 
Corona $^{35}$, lo que fue causa de que algunas familias, constituidas como linajes, se distanciaran del resto de omes buenos del Común para autoafirmarse como elite de poder ${ }^{36}$. Esto fue acompañado de cambios en la manera en que se llevaba a cabo la elección de los oficiales del concejo, que quedó como prerrogativa de los pecheros más quantyados u omes buenos.

En algunas villas portuarias, como Santander y Laredo, con anterioridad a la instauración del Regimiento, la elección de los cargos concejiles se realizaba por medio de un sistema que se denominaba «boses». En Laredo, los alcaldes, fieles y otros oficiales se elegían anualmente para representar a las sesenta o setenta boses de los pecheros más quantiados de la dicha villa; es decir, a los vecinos que pagaban los impuestos más altos. Estos sesenta o setenta pecheros más quantiados de Laredo iban de dos en dos a un sitio cercano al cementerio de la iglesia parriquial de Santa María, donde prestaban juramento y decían en voz alta los nombres (boses) de los que ostentarían los cargos concejiles, delante de los alcaldes, el merino, el escribano y dos mayordomos de la cofradía de San Martín. Tras ello, los oficiales del concejo salientes hacían un recuento del número de boses en la iglesia de Santa María, y salían escogidos quienes más boses hubiesen recibido, los cuales debían prestar juramento ${ }^{37}$.

El sistema de rotación anual de los cargos concejiles, así como que los oficiales entrantes en el concejo hubieran de ser elegidos por los sesenta pecheros más quantiados de Laredo, trajo consecuencias en el sistema de provisión de los oficiales. En principio, ello facilitó el reparto equitativo entre los integrantes del grupo de poder, pero el hecho de que los principales magistrados concejiles intervinieran directamente en el proceso electivo, basado en la cooptación, permitió que determinados miembros de la elite urbana ocuparan el gobierno concejil durante años; si bien, el hecho de que los omes buenos eligiesen los cargos del concejo, aunque tuvieran que hacerlo entre los linajes, los situaba dentro de sus redes clientelares, es decir dentro del sistema político imperante ${ }^{38}$. Sin embargo,

${ }^{35}$ ARRIAZA, A., «Le statut nobiliaire adapté à la bourgeoisie: mobilité des statuts en Castille à la fin du Moyen Age», en Le Moyen Age, 1995, 1, p. 96.

${ }^{36}$ MONSALVO ANTON, J. M., «Parentesco y sistema concejil. Observaciones sobre la funcionalidad política de los linajes urbanos en Castilla y León (siglos XIII-XV)». Hispania, 53/185, 1993, pp. 937-969. JARA FUENTE, J. A., «Sobre el concejo cerrado: Asamblearismo y participación política en las ciudades castellanas de la Baja Edad Media (conflictos inter o intra-clase)», en Studia Historica. Historia Medieval, 17, 2000, pp. 113-136.

37 SOlÓRZANO TELECHEA, J.A., Documentación medieval en la Biblioteca Municipal de Santander. Manuscritos originales (945-1519). Anales de Historia Medieval de la Europa Atlántica (anejo 1), 2007, doc. 23.

${ }^{38}$ MONSALVO ANTÓN, J.M ${ }^{\text {a }}$, «La sociedad política en los concejos castellanos de la Meseta durante la época del regimiento medieval. La distribución social del poder», en Concejos y ciudades en la Edad Media hispánica. 1990, pp. 359-413. 
entre finales del siglo XIV y principios del XV, se fraguó la configuración oligárquica del concejo, consolidando en el poder concejil a una minoría de los omes buenos, que contaba con la experiencia de haber ostentado cargos concejiles desde finales del siglo XIII, gracias a su fama y riqueza y que, a principios del siglo $\mathrm{XV}$, ve reconocido ese papel dominante mediante sanción regia ${ }^{39}$.

En el último cuarto del siglo XIV, los linajes familiares, constituidos dentro del grupo de los omes buenos, se arrogaron todos los cargos concejiles, al mismo tiempo que dejaron de lado a aquellos vecinos, que pertenecían al grupo de omes buenos y pecheros quantyados, pero cuya condición pechera les impedía el acceso a la oligarquía, integrada sólo por linajes. Así pues, si bien en la génesis de las elites urbanas habían confluido tanto propietarios de tierras, como gentes dedicadas al comercio y a oficios diversos, es decir, aquel grupo que se reconocía con el calificativo de omes buenos, el desarrollo de la idea de linaje con las connotaciones de la antigüedad, la honra y la sangre pronto llevó a este grupo a diferenciarse de aquellas personas que, aun perteneciendo al grupo de los omes buenos, no supieron seguir el ritmo impuesto por la creciente potenciación de otros miembros de esa minoría de hombres buenos. Esos pocos linajes, aún a principios del siglo XV, se denominaban omes buenos de los linages ${ }^{40}$. Los omes buenos del Común, por su parte, hasta la introducción del regimiento, habían desempeñado un papel destacado, pues los parientes mayores los necesitaban, -ya que los cargos concejiles eran elegidos por las boses de los omes buenos del Común-, pero cuando Enrique III y Juan II sancionaron el régimen de elección de los oficiales por vía de bando e linaje, los omes buenos dejaron de ser útiles; de tal manera, que quedaron excluidos de los cargos concejiles, al no estar integrados en el sistema de bandos de los parientes mayores, que influían en la nominación de los oficiales ${ }^{41}$.

La clara vinculación de los cargos concejiles con un número determinado de linajes cerró el acceso a los cargos concejiles a todos aquellos que no pertenecieran a ciertos linajes o a sus clientelas. En las Cuatro Villas de la Costa de la Mar, los linajes de los Escalante y los Calleja (Santander), los de La Obra/ Pelegrines y los Villota (Laredo), los Marroquines y los Amorós (Castro Urdiales) y Corro de Arriba y de Abajo (San Vicente de la Barquera) se consolidaron como una oligarquía en sus respectivas villas durante el último cuarto del siglo XIV,

${ }^{39}$ BONACHÍA HERNANDO, J.A. «Crisis municipal, violencia y oligarquías en Burgos a comienzos del siglo XV», en La Península Ibérica en la Era de los descubrimientos 1391-1492. Actas III Jornadas Hispano-Portuguesas de Historia Medieval (1991). 1997, p. 1082.

40 SOLÓRZANO TELECHEA, J.A., Documentación medieval en la Biblioteca Municipal..., op. Cit, doc. 23.

${ }^{41}$ QUINTANILLA RASO, Ma C., «Política ciudadana y jerarquización del poder: bandos y parcialidades en Cuenca», en la España Medieval, 20, 1997, p. 225. 
apartando del sistema político local a los omes buenos del Común ${ }^{42}$. Así, la fuente fundamental de conflictos locales estuvo protagonizada por las rivalidades internas entre los linajes, que componían la oligarquía, que organizados en bandos trastocaron la convivencia en las villas ${ }^{43}$. En Laredo, los conflictos banderizos entre los Obra-Pelegrines y los Villota se produjeron tras la muerte del pariente mayor, Juan Fernández de la Obra, a finales del siglo XIV, quien dejó como herederos a sus dos hijos, de tres y cinco años respectivamente. Los hombres buenos del linaje de Villota aprovecharon la debilidad del bando contrario para hacerse con todos los cargos concejiles, apoyados por los hombres buenos del Común. El conflicto acabó en un enfrentamiento armado, en la Rúa Mayor, entre ambos bandos, en el cual murieron varios vecinos en 1402. Sin embargo, el conflicto no devolvió las cosas a su orden y tres años después, el bando de los linajes de Pelegrines/Obra recurría a Enrique III para reclamar su derecho a nombrar la mitad de los cargos concejiles que les correspondía por uso e costumbre, lo cual fue confirmado por este monarca. Pero en esta ocasión, el problema había crecido con la incorporación de los omes buenos del Común a la lucha por el poder. En 1405, la sentencia arbitral de Enrique III sobre el litigio entre los omes buenos del Común y los omes buenos del linage de Villota, de una parte, y los omes buenos del linage de Pelegrín/Obra de otra, sobre la incorporación o no de los segundos al gobierno concejil, dio la razón a los segundos, lo que suponía la oligarquización del concejo de Laredo, siendo éste el sistema de gobierno que se estableció hasta que la reina Isabel lo modificó en $1497^{44}$. A partir de ese momento, las elecciones concejiles no se volvieron a hacer a voz de concejo; es decir, en nombre de toda la comunidad, lo que -según denunciaba el Común- deslegitimaba las acciones emprendidas por los omes buenos de los linages y, por otro, desautorizaba la elección de los oficiales, ya que éstos eran nombrados únicamente por los linages, por lo que no representaban a la comunidad. En este momento observamos, además, la presencia de un par de vocablos -común y liga-, que son los primeros testimonios de la existencia de una asociación juramentada antioligárquica de defensa de los intereses populares en Laredo, que revela la existencia de dos identidades contrapuestas $^{45}$.

${ }^{42}$ MíNGUEZ, J.Ma ., «La transformación social de las ciudades y las Cortes de Castilla y León», en Las Cortes de Castilla y León en la Edad Media, vol. II, 1988.

${ }^{43}$ QUINTANILLA RASO, M ${ }^{a}$.C., «Facciones, clientelas y partidos en España en el tránsito de la Edad Media a la modernidad», en ALVARADO, J. (coord.) Poder, economía y clientelismo. Madrid, 1997, pp. 15-50.

${ }^{44}$ SOLÓRZANO TELECHEA, J.A., Documentación medieval en la Biblioteca Municipal..., op. Cit, doc. 23.

45 GUTIERREZ NIETO, J.I., «Semántica del termino 'comunidad' antes de 1520: las asociaciones juramentadas de defensa», en Hispania, 136, 1977, pp. 320-367. 
El triunfo del regimiento como mecanismo básico del gobierno urbano, sancionando el monopolio del poder político por parte de la oligarquía urbana, organizada en bandos y linajes, que conllevó la relegación de las esferas de poder del Común ${ }^{46}$, fomentó la toma de conciencia de su condición superior, una identidad diferenciada de la del resto de la población, causa de la frustración del resto de vecinos, una vez que fueron conscientes del origen de los mecanismos de su discriminación: la no pertenencia a unos determinados linajes, a unas estructuras sociopolíticas basadas en el parentesco, ya real, ya ficticio ${ }^{47}$. A pesar de sus diferencias internas, las oligarquías de linajes cerraron filas frente a lo que consideraban un ataque exterior por parte del Común. La repuesta que dieron los linajes de San Vicente de la Barquera a las reivindicaciones del Común a finales del XV, nos informe del sentimiento identitario cívico de la oligarquía: «los honrados linajes antiguos que esta villa poblaron conforme a las leis de sus altezas e al buen uso e costumbre antigua tenyan e tovieron de syempre acá de alegir los tales ofiçiales al pro e bien común del pueblo... conforme al privillejo que diz que tienen e de los linajes en él contenidos e de los más ricos y honrrados en la qual dicha posesyón diz que han estado y estovyeron sus antepasados de dyez, e veynte, e treynta, e quarenta e çinquenta, e sesenta e çient annos a esta parte, consyntyéndolo e sabyéndolo los vesynos de esta dicha villa» ${ }^{48}$.

El derecho a gobernar las ciudades y villas por parte de los parientes mayores de los linajes se basaba en la idea de que la honra y la antigüedad legitimaban a unos pocos para regir la política de la comunidad. Asimismo, el honor del bando-linaje se extendió al territorio que controlaban. Cuando, en 1488, los vecinos de la Puebla Vieja de Santander acusaron a los de la Puebla Nueva de haber destituido a sus oficiales en el concejo, y haber nombrado otros sin su consentimiento, los de la Puebla Nueva, parientes, consortes y convecinos, alegaron que ello era justo, legytimo e nesçesaria defensión e honor de la dicha villa e Puebla Nueva, que era casy toda la villa, ya que la parte acusadora no representaba la décima parte de la población. En el caso de Santander, así como de otros centros urbanos portuarios, los linajes crearon un imaginario urbano que los favorecía, al conseguir de Enrique IV el título de «Noble y Leal» para esta villa en 1467, pues

${ }^{46}$ MONSALVO ANTON, J. M. «Gobierno municipal, poderes urbanos y toma de decisiones en los concejos castellanos bajomedievales (consideraciones a partir de concejos salmantinos y avulenses)», en Las sociedades urbanas en la España Medieval. XXIX Semana de Estudios Medievales. Estella 15-19 julio 2002, Pamplona, Gobierno de Navarra, 2003, pp. 409-487.

${ }^{47}$ VAL VALDIVIESO, M ${ }^{a}$.I. «Elites urbanas en la Castilla del siglo XV (Oligarquía y Común)», en THEMUDO BARATA, FH. (ED.) Elites e redes clientelares na Idade Media. Lisboa, 2001, pp. 71-89.

48 Archivo General de Simacas, Cámara Castilla, Pueblos, leg. 18, fol. 334; 1495, 01, 19. (En Adelante, A.G.S.). 
la finalidad consistía en hacer una semejanza entre biografía linajuda e «historia urbana», en la que no faltaba una determinada intencionalidad comparativa entre ambos procesos. Desde el momento en que se reconocía la existencia de una honra propia de la villa, se legitimaba el papel de los que ostentaban los cargos concejiles $^{49}$, cuya misión era acrecentar la honra de la villa, y los que mejor podían cumplir esa tarea eran los linajes, cuyos miembros eran los más honrados por definición. El epíteto de noble venía, así, a exaltar la genealogía tanto de los centros urbanos como de los linajes que los gobernaban.

La progresiva instauración del sistema regimental en las villas portuarias intensificó la polarización social entre las oligarquías urbanas y el conjunto de vecinos, el Común. A lo largo del siglo XV, el crecimiento de las poblaciones urbanas y la prosperidad creciente de ciertos sectores sociales del Común conllevaron la necesidad de elaborar un nuevo sentimiento de identidad urbana, alejada de la identidad cívica de las oligarquías urbanas. La identidad, digamos oficial, creada por la oligarquía quedó apartada, ya que no podía integrar a ciertos sectores sociales en ascenso -propietarios, rentistas, comerciantes, miembros de profesiones liberales- poco o nada susceptibles a identificarse con la tradición cívica o familiar de las oligarquías de linajes.

Así, las comunidades urbanas hubieron de potenciar nuevos sentimientos de solidaridad que se unieran a los factores de habitar en un mismo lugar, compartir las mismas actividades y regirse por las mismas leyes. El espíritu colectivo de los habitantes urbanos se manifestó por distintos cauces, pero muy especialmente a través de nuevas formas de asociación y nuevas expresiones. En el siglo XV, aparecieron en la documentación varios vocablos relacionados entre sí -común, cofradía, pueblo, comunidad, república-, que designaban al conjunto de vecinos, carentes de privilegios, cuya dedicación profesional era muy diversa, -artesanos, pescadores, mercaderes, agricultores, calafates, herreros, carniceros...-, que con cierta organización ejercieron una defensa conjunta de sus intereses. Todas estas expresiones se revelan como entidades aglutinadoras de todos los vecinos que estaban excluidos de las instituciones de decisión política urbanas, tras la instauración del regimiento.

En las villas portuarias, las cofradías religiosas y profesionales tuvieron un papel determinante en la conformación de la identidad del Común en el siglo

49 BLICKLE, P. (ed.), Resistance, Representation, and Community. Oxford, 1997. BLOCKMANS, W., «Representation», en ALLMAND, C. (Ed.), The New Cambridge Medieval History. Vol. VII. c. 1415 - c. 1500, Cambridge 1998, pp. 29-64. CARRETERO ZAMORA, J., «Representación política y procesos de legitimación», en NIETO SORIA, J. M. (ed.), Orígenes de la monarquía hispánica: Propaganda y legitimación (ca. 1400-1520). Dikynson, Madrid, 1999, pp. 177-205. 
$\mathrm{XV}^{50}$. La existencia de una institución consolidada en estos puertos como la cofradía, en la que estaba encuadrada la mayor parte de la población no privilegiada, con reuniones frecuentes, se ofrecía como el mejor instrumento para canalizar las acciones del común. En Laredo, a partir de los años 40 del siglo $\mathrm{XV}$, hallamos que la cofradía se había convertido en sinónimo de comunidad y pueblo, en el sentido de asociaciones juramentadas en defensa de la vecindad. En 1443, la cofradía de San Martín de Laredo se dirigía a Juan II de la siguiente manera: «cofrades y omes buenos de la cofradía de San Martín, pueblo y comunidad de esa dicha villa de Laredo $»^{51}$, para denunciar que habían sido elegidos dos omes poderosos y mayores, como fieles y juramentados del concejo, sin contar con los procuradores y comunidad y cofrades de la dicha villa, y que habían sido nombrados fieles y tasadores unos vecinos que pusieron precio a los pescados, lo que contravenía sus privilegios, pues los pescados frescos y salados se habían vendido libremente «so el Palacio sin tasa ni peso» desde tiempo inmemorial ${ }^{52}$. De esta manera, los cofrades actuaban como la voz del pueblo y la comunidad de Laredo.

El último paso en la conformación de la identidad del Común se produjo a partir del reinado de Enrique IV y en especial del de los Reyes Católicos. A finales del siglo XV, el Común ya había sido derrotado políticamente, varias veces, tras la instauración del regimiento, las concordias y las distintas sentencias arbitrales otorgadas por los adelantados de Castilla y de León, que consolidaban un reparto del poder en beneficio de las oligarquías de linajes ${ }^{53}$. En respuesta a esta situación, el Común se organizó para defender sus derechos, lo que consolidó un sentimiento de identidad del común. A partir de la década de los años 80 , la comunidad se nos revela con una renovada vitalidad y conciencia de sí misma, dirigiendo sus quejas y reivindicaciones directamente a los monarcas, sin hacer uso de las cofradías u otras entidades, aunque con algunos matices, pues dado que cofradía y comunidad venían siendo sinónimos, la comunidad va a reivindicar los derechos políticos de las cofradías ${ }^{54}$.

${ }^{50}$ MONSALVO ANTON, J. M., «Solidaridades de oficio y estructura de poder en las ciudades castellanas de la Meseta, durante los siglos XIII al XV (aproximación al estudio político del corporativismo artesanal)», en El trabajo en la Historia. Séptimas Jornadas de Estudios Históricos. Salamanca, 1996, pp. 39-90.

${ }^{51}$ CUÑAT CISCAR, V. Documentación.... op. cit. doc. 88; 1443.

${ }^{52}$ VAL VALDIVIESO, Ma. I.: «Oligarquía 'versus' Común (consecuencias sociopolíticas del triunfo del regimiento en las ciudades castellanas)», en Medievalismo, 4, 1994, pp. 41-58.

53 VAL VALDIVIESO, M.I., «Oligarquía versus común...», op. Cit., pp. 56-57,

${ }^{54}$ RACINE, P.: «Le 'popolo', groupe sociale ou groupe de pression?», en Nuova Rivista Storica, LXXIII, n.1-2, pp. 133-150. MICHAUD-QUANTIN, P.: Universitas. Expressions du mouvement communautaire dans le Moyen Age. París, 1997. 
El Común, a través de su expresión identitaria de Pueblo y Comunidad, en las dos últimas décadas del siglo XV se constituyó en una entidad con personalidad jurídica propia, con un sentido profundo de reivindicación política y de antagonismo respecto al poder político de la oligarquía de linajes ${ }^{55}$. Bilbao fue el primer puerto norteño en donde se llevó a cabo la reforma del sistema político. La villa estaba destrozada a causa de las luchas banderizas de los parientes mayores de los Gamboa, Oñez, Leguizamon, Zurbarán, Arbolancha, entre otros. En concreto, la villa de Bilbao solicitó a los monarcas la aplicación de las Ordenanzas dadas a Vitoria en 1476. Ante esta petición, Isabel y Fernando enviaron, en 1483, al licenciado García López de Chinchilla, del Consejo Real, para resolver el asunto. Chinchilla y las personas elegidas para este cometido por el concejo elaboraron un capitulado basado o inspirado en el otorgado a Vitoria. Este primer Capitulado de Chinchilla de 22 de noviembre de 1483, confirmado por los reyes en febrero de 1484, en sus apartados quinto y octavo adoptaba medidas para evitar la parcialidad en la elección de los oficiales y en el gobierno de la villa ${ }^{56}$. Los nuevos sistemas electorales se fueron asentando por las villas portuarias: en San Sebastián, en 1489; en Avilés, en 1493; en Fuenterrabía en 1496, etc ${ }^{57}$.

En Laredo, en agosto de 1495, Juan de Escalante, por sí y en nombre de otros vecinos de esa villa, denunció que los parientes mayores de los linajes elegían y nombraban a sus parientes y criados como miembros del concejo, aun cuando no eran personas hábiles, y lo hacían para poder llevarse el dinero de las arcas concejiles en beneficio propio. Además, los parientes mayores obviaban la existencia de un grupo de «hombres hijosdalgo, çibdadanos de grandes fasyendas, buena fama e mucha conçiencia», que sabrían gobernar la villa en serviçio y bien e provecho de la república. Es decir, había un sector de la población que reunía los requisitos identitarios para poder participar del gobierno urbano, pero que estaba excluido. Por todo ello, solicitaban de los reyes que el corregidor les informara de lo que estaba ocurriendo, que pidieran cuentas sobre la gestión económica del concejo, que los parientes mayores mostraran los títulos que tenían para poder nombrar los cargos concejiles y que éstos no se eligiesen por los bandos ${ }^{58}$. Al mes siguiente, los monarcas daban la razón a Juan de Escalante y ordenaban que

55 VAL VALDIVIESO, I., «Aspiraciones y actitudes sociopolíticas. Una aproximación a la sociedad urbana de la Castilla bajomedieval», en La ciudad medieval: aspectos de la vida urbana en la Castilla bajomedieval, Valladolid, 1996, pp. 213-254.

${ }^{56}$ POLO MARTíN, R., «Los Reyes Católicos y la insaculación en Castilla», en Studia Histórica. Historia Medieval, 17, 1999, pp. 137-197.

${ }^{57}$ GARCÍA FERNÁNDEZ, E., Gobernar la ciudad en la Edad Media: oligarquías y elites urbanas en el País Vasco. Vitoria, 2004. VV.AA., El triunfo de las elites urbanas guipuzcoanas: nuevos textos para el estudio del gobierno de las villas y de la provincia (1412-1539). San Sebastián, 2002.

${ }^{58}$ AGS, RGS, vol. XII, fol. 276; 1495, 08, 26. 
la villa fuera gobernada por los «ombres de seso, buena conçiecia e sin parçialidad». Sin embargo, los parientes mayores hicieron caso omiso de la orden real y Juan de Escalante denunciaba que no se respetaba el mandato regio. En esta ocasión, la protesta la «elevaba por sí e en nombre de la república e comunidad e commo una persona del pueblo» ${ }^{59}$. Tras lo cual, dos años después, en 1497, los Reyes Católicos, aduciendo la denuncia puesta por Juan de Escalante, vesino de la dicha villa, por sy e en nombre de la república e comunydad de la dicha villa e commo una persona del pueblo, reformaron totalmente el sistema de elección concejilio ${ }^{6}$. Un argumento ético, el de la Comunidad, que proporcionaba una excusa perfecta para luchar contra la oligarquía parental.

En San Vicente de la Barquera, en 1494, los Reyes Católicos requirieron información sobre los bandos y el gobierno de la villa a partir de dos denuncias que presentaron Pedro Ruiz Román, commo uno del pueblo e por el bien público de ella y Juan de Oreña. Según su testimonio, en la villa había dos linajes que nombraban los oficiales del concejo de entre sus parientes y linajes, los cuales eran hombres indoctos e apasionados que no sabían gobernar la villa, cuando, por otra parte, había personas ricas, llanas, abonadas y diligentes y de buena fama para hacerlo, pero estaban apartadas del gobierno del concejo debido a que no eran de linaje, bando, apellido y parçialidad, a lo que se sumaba que se aprovechaban de las rentas y provocaban ruidos, muertes y heridas, por lo que la villa estaba mal gobernada. Ese mismo año, ante la grave situación por la que atravesaba la villa de San Vicente, los Reyes Católicos introdujeron las nuevas ordenanzas electorales, que instituía el sistema de insaculación para regular el acceso a los cargos concejiles.

Desde finales del siglo XV, la política interior de las villas portuarias estuvo presidida por la idea del bien común, que conllevó implícitamente el principio de limitación del beneficio personal a favor de los intereses generales de la comunidad. Así, en 1496, cuando la cofradía de San Vicente volvió a dirigir sus quejas a los Reyes Católicos, ya que a pesar de los privilegios de la cofradía y a que, en 1494, los monarcas habían modificado el proceso de elección de cargos concejiles, ésta no tenía representación. La cofradía alegaba que de los ochocientos vecinos que había en la villa, setecientos pertenecían a la cofradía, y aun con ello los cargos concejiles se repartían entre los otros cien vecinos, que agrupados en bandos y linajes se los echaban a suertes sin contar con el resto de los vecinos, algunos de los cuales eran tan «ábiles, subfiçientes, ricos e abonados como los otros vecinos para ostentar los cargos en lo qual la comunidad de la dicha villa e de la

\footnotetext{
${ }^{59}$ AGS, RGS, vol. XIII, fol. 41; 146, 11, 08.

${ }^{60}$ Archivo de la Real Chancillería de Valladolid, Reales Ejecutorias, c. 286-32; 1497, 09, 20.
} 
mayor parte de la dicha confradía resçibian mucho agravio e danno», ya que además no les respetaban la costumbre inmemorial de elegir y nombrar dos regidores, de los seis que había, en representación de la cofradía. Los Reyes Católicos ordenaron al concejo que los cargos concejiles no fueran nombrados por los bandos y linajes, y que en el concejo hubiera vecinos de todos los estados de ella, siempre que fueran ábiles e subfiçientes ${ }^{61}$. No obstante, las exigencias del Común no se dirigían contra un sistema social estratificado, sino que iban destinadas a obtener lo que es justo y equitativo para el 'estado de la Comunidad' en el seno de un sistema de desigualdades.

La antigua oligarquía de linajes se opuso al cambio de sistema y, por lo tanto, a las nuevas normas sobre elección de los cargos concejiles ${ }^{62}$. En 1495, Gonzalo Bravo, en nombre de los linajes que gobernaban el concejo de San Vicente de la Barquera, alegó que, aunque acataban la nueva normativa regia, las denuncias presentadas contra ellos no eran ciertas, que todo se había llevado en secreto, y que los Reyes no conocían la verdad de lo que sucedía «espeçialmente de commo los honrados linajes antiguos que esta villa poblaron conforme a las leis de sus altezas e al buen uso e costumbre antigua tenyan e tovieron de syempre acá de alegir los tales ofiçiales al pro e bien común del pueblo... conforme al privillejo que diz que tienen e de los linajes en él contenidos e de los más ricos y honrrados en la qual dicha posesyón diz que han estado y estovyeron sus antepasados de dyez, e veynte, e treynta, e quarenta e çinquenta, e sesenta e çient annos a esta parte, consyntyéndolo e sabyéndolo los vesynos de esta dicha villa» ${ }^{63}$. Por su parte, Juan de Urueña, en nombre de la comunidad y república de San Vicente y como uno del pueblo, defendía la reforma "porque ella diz que se quitan los vandos e parcialidades e robos e tyranias e cohechos» y comenta que si los monarcas la derogasen sería «cosa de mal enxenplo que aviendo seydo quitados los vandos e parcialidades en todos nuestros reygnos que en la dicha villa a respeto de quinze e veynte onbres aya continuadamente los dichos vandos para repartir entre sy los dichos oficios» ${ }^{64}$.

La identidad política del Común difería de la de los linajes, que traspasaban los cargos de regidores a hijos y familiares dentro del linaje, sin tener que dar cuenta de ello al resto de la población urbana. Las quejas del Común residían en que los regidores gobernaban por intereses personales y no de acuerdo al principio del bien común. El discurso del Común enarboló la defensa de lo público frente a lo privado, basada en la idea de la participación equitativa de los estados

\footnotetext{
${ }^{61}$ A.G.S., R.G.S., vol. XIII, fol. 142; 1496, 03, 24.

62 VILLAPALOS SALAS, G., Justicia y monarquía. Puntos de vista sobre su evolución en el reinado de los Reyes Católicos. Madrid, 1997, p. 149 y ss.

63 A.G.S., Cámara Castilla, Pueblos, leg. 18, fol. 334; 1495, 01, 19.

${ }^{64}$ A.G.S., R.G.S., vol. XII, fol. 128; 1495, 03, 01.
} 
y en los intereses generales de la comunidad. Frente a este ideario identitario del Común, los linajes blandieron el suyo, sustentado en la costumbre, la tradición y los privilegios de los linajes.

$* * *$

Sobre estos elementos de la identidad del hecho urbano del norte peninsular se consolidó la red de villas portuarias en la fachada Cantábrica, que constituyó un proceso lento, que necesitó del apoyo de la monarquía primero y después de las instituciones de gobierno locales, así como del conjunto del Común. 